\title{
O bebê com síndrome de Down na educação infantil: um estudo de caso
}

\author{
Rogério Drago* \\ Israel Rocha Dias**
}

\section{Resumo}

Esse artigo tem como objetivo principal descrever o processo de inclusão de um bebê com síndrome de Down matriculado numa escola comum de Educação Infantil. O referencial metodológico adotado assumiu o panorama do estudo de caso com enfoque descritivo numa perspectiva histórico-cultural, dialogando essencialmente com Vigotski e seus seguidores, que consideram o bebê como sujeito sócio-histórico-cultural imerso na sociedade macro como sujeito cognoscente. O estudo foi desenvolvido numa escola federal de educação infantil pertencente e pelo levantamento dos dados, enfatiza-se que o sujeito com síndrome de Down apresenta características, peculiaridades e particularidades que são próprias do acidente cromossômico que causa (ainda sem conclusão médica) a síndrome de Down, entretanto, quando a escola de educação infantil e seus profissionais entendem que o bebê com ou sem deficiência é sujeito produtor de história e cultura, protagonista de seu processo, tendem a trabalhar no sentido de que esse sujeito pode e deve fazer parte de todo o cotidiano como membro ativo do processo de ensino-aprendizagem. Além disso, a pesquisa evidenciou que as práticas pedagógicas desenvolvidas cotidianamente davam conta de conduzi-lo ao desenvolvimento de suas funçóes psicológicas superiores, na medida em que participava ativamente de tudo aquilo que era proposto.

Palavras-chave: Inclusão; Bebê com síndrome de Down; Educação infantil.

* Professor doutor da Universidade Federal do Espírito Santo, Vitoria, Espírito Santo, Brasil.

** Doutorando em Educaçáo pela Universidade Federal do Espírito Santo, Vitoria, Espírito Santo, Brasil. 


\section{Baby with Down syndrome in early childhood education: a case study}

\section{Abstract}

This article aims to describe the process of adding a baby with Down syndrome enrolled in a regular school Early Childhood Education. The adopted methodological approach took the picture of the case study with descriptive approach a historicalcultural perspective, talking mainly with Vygotsky and his followers, who consider the baby as the subject socio-historical-cultural immersed in the macro society as knower. The study was developed in a federal school kindergarten and the survey data, it emphasizes that the subject with Down syndrome has features, quirks and characteristics that are unique to the chromosomal accident that causes (even without medical conclusion) Down syndrome, however, when the school of early childhood education and its professionals understand the baby with or without disabilities is subject producer of history and culture, protagonist of his process, tend to work in the sense that this guy can and should be part of all routine as an active member of the teaching-learning process. In addition, the research showed that the developed pedagogical practices every day they realized lead him to the development of their higher mental functions, to the extent that participated actively in all that was proposed.

Keywords: Inclusion; Baby with Down syndrome; Childhood education.

\section{Introdução}

Este artigo tem como objetivo central descrever o processo de inclusão de um bebê com síndrome de Down matriculado numa escola comum de Educação Infantil. Para tanto, parte de um estudo de caso junto a uma escola comum de educação infantil denominada CEI Criarte, pertencente à rede federal de educação e como objetivos específicos pretendeu-se: descrever as principais características, peculiaridades e particularidades da síndrome de Down; compreender, no contexto da educaçáo infantil, as práticas pedagógicas desenvolvidas com foco na inclusão do bebê com síndrome de Down; descrever e problematizar os modos de organização de uma escola de educação infantil federal para o atendimento e inclusão do bebê com síndrome de Down.

Metodologicamente, desenvolve-se por meio de um estudo de caso de cunho sócio-histórico, tendo como procedimentos de produção de dados a observação participante, entrevistas semiestruturadas e análise documental. Foram sujeitos do estudo: um bebê com síndrome de Down em processo de inclusão na educação infantil, as profissionais do CEI que lidavam diretamente com ele e seus familiares.

$\mathrm{O}$ artigo encontra-se assim organizado: na primeira parte do trazemos a caracterizaçáo da síndrome de Down em seus aspectos fenotípicos e genotípicos. No segundo tópico abordamos alguns conceitos acerca da educação infantil e educação inclusiva que nortearam a pesquisa que deu origem ao artigo. No terceiro tópico 
discutimos brevemente a base teórica que sustentou a pesquisa e sua relação com o processo de aprendizagem e desenvolvimento do bebê. No quarto item trazemos a descrição metodológica do estudo realizado e, em seguida, relatamos os dados a partir das observaçôes e entrevistas realizadas no cotidiano da escola de educação infantil onde o bebê estava matriculado.

\section{Caracterização da síndrome de Down}

De acordo com Voivodic (2007), os sujeitos com síndrome de Down (SD) têm como característica principal a deficiência intelectual, o que, segundo a autora, demonstra a complexidade e a importância de sua educação, mas não quer dizer que seu processo educativo seja impossível. Pois, segundo Vigotski (2001, p. 284), "o indivíduo náo deve ser entendido como forma acabada, mas como uma permanente e fluente forma dinâmica de interação entre o organismo e o meio".

A síndrome de Down pode ser caracterizada, como uma desordem genética, resultado de uma alteração genética numérica. Nas células humanas existem 46 cromossomos, que são divididos em 23 pares, mas no sujeito com síndrome de Down, devido a esta alteraçáo, existem 47 cromossomos divididos em 23 pares, estando o cromossomo extra, ligado ao par 21. Essa alteraçáo cromossômica traz uma série de particularidades que caracterizam a síndrome em questão.

Dentre as principais características pode-se destacar, além da deficiência intelectual: cabeça grande, pés achatados, mãos pequenas, obesidade, nariz pequeno, hipotonia muscular, descamação da pele, estrabismo, catarata, pescoço curto, problemas cardiovasculares, dentre uma série de outras especificidades que, associadas, podem fazer com que tais indivíduos tenham problemas de ordem orgânica que podem interferir em seu desempenho acadêmico. Daí a necessidade de se conhecer profundamente estas características, para que tais indivíduos náo sejam vistos somente em seus aspectos biológicos, mas como sujeitos cognoscentes, já que a síndrome de Down é a principal causa de deficiência intelectual cromossomicamente comprovada.

Diante das características fenotípicas e genotípicas da síndrome de Down, é muito importante enfatizar que nem toda criança com síndrome de Down exibe todas essas características. Umas sáo mais acentuadas em algumas crianças do que em outras. Com isso, embora todas as crianças com SD possam ser reconhecidas por sua aparência física, nem todas parecem iguais, essas aparências podem se modificar com o decorrer do tempo (PUESCHEL, 1993).

Portanto, tais características precisam ser observadas, porém não podem ser impeditivas para que esses sujeitos sejam vistos como seres que produzem e possuem história e cultura, membros ativos da sociedade. Ou seja, as características biológicas não podem ser impeditivas das características sociais.

\section{Educação infantil e educação inclusiva: breves conceitos}

Tratar da educação infantil é refletir sobre um modo de se pensar a educação para sujeitos que historicamente têm tido este direito negado por uma série de fato- 
res que vão desde o não reconhecimento da criança como sujeito de direito, como adulto em miniatura, como ser angelical que precisa de cuidado, como futuro da nação, como ser que pode ou não vingar, dentre uma série de concepçôes marcadas por contextos históricos e sociais ambíguos e paradoxais.

Falar em educação infantil é falar também na criança como sujeito que emerge da obscuridade, já que como destaca Ariés (1981), até por volta do século XIV a ideia de infância não existia. Logo, de acordo com o autor, parece que a ideia de uma educação para infância também era inexistente. $\mathrm{O}$ entendimento e ressignificação da criança como sujeito social e histórico têm contribuído para que a educação infantil assuma, no contexto brasileiro, o status de primeira etapa da educação básica (BRASIL, 1996; 2010).

As Diretrizes Curriculares Nacionais para Educação infantil - DCNEI (BRASIL, 2010), em consonância com a Lei de Diretrizes e Bases da Educação no. 9.394/96, definem a Educação Infantil como sendo,

Primeira etapa da educação básica, oferecida em creches e pré-escolas, às quais se caracterizam como espaços institucionais nẫo domésticos que constituem estabelecimentos educacionais públicos ou privados que educam e cuidam de crianças de 0 a 5 anos de idade no período diurno, em jornada integral ou parcial [...].

Para grande parte das crianças, a escola tem sido o único referencial que elas têm como acesso ao conhecimento formal e sistematicamente construído, então, entendemos que para que essa criança não seja invisibilizada como sujeito de direito, o professor precisa tornar o ensino desse sujeito algo interessante, atrativo, criativo, instigando a criança em sua curiosidade e em seu desejo de aprender.

No que pese à educação inclusiva, o processo de visibilização das pessoas com deficiência e sua chegada às escolas comuns não tem sido um processo fácil. Durante muito tempo, tais sujeitos viveram um movimento que pode ser denominado de integração. Nesse processo, "[...] não há pressuposição de mudança na escola e, consequentemente, do ensino". (MENDES, 2002, p. 64)

Por outro lado, atualmente tem ganhado força no contexto brasileiro e mundial a ideia de que as pessoas com deficiência, transtornos globais do desenvolvimento e altas habilidades ou superdotação, que compóem o público- alvo da educação especial, precisam estar na escola comum recebendo um ensino que não os distanciem desse contexto, onde possam participar da vida comum em todas as suas possibilidades. Tal processo tem sido caracterizado pela inclusão.

De acordo com Prieto (2006, p. 40),

[...] o objetivo na inclusão escolar é tornar reconhecida e valorizada a diversidade como condiçáo humana favorecedora da aprendizagem. [...] a ênfase deve recair sobre a identificação de suas possibilidades, culminando com a construção de alternativas para garantir condiçôes favoráveis à sua autonomia escolar e social, enfim, para que se tornem cidadáos de iguais direitos. [...] A edu- 
cação inclusiva tem sido caracterizada como um 'novo paradigma', que se constitui pelo apreço à diversidade como condição a ser valorizada, pois é benéfica à escolarização de todas as pessoas, pelo respeito aos diferentes ritmos de aprendizagem e pela proposição de outras práticas pedagógicas, o que exige ruptura com o instituído na sociedade e, consequentemente, nos sistemas de ensino.

Diante disto, quando se pensa em inclusão no campo educacional, precisa-se ter como prioridade os sujeitos que vamos trabalhar na sala de atividades, buscando alternativas sobre como podemos garantir a eles, uma educação que lhes permita aprender e se desenvolver socialmente.

A partir dessas ideias, pode-se salientar que a educação especial numa perspectiva inclusiva em associação à educação infantil, é um modo de reconhecer que todos os sujeitos, independente da idade ou condiçáo biológica, são capazes de aprender, produzir, reproduzir e deixar suas marcas culturais.

\section{O bebê com deficiência à luz dos pressupostos histórico- culturais}

Trabalhar o processo de inclusão de um bebê com síndrome de Down na educação infantil é trabalhar também com o processo de construção desse sujeito como um ser histórico e cultural, daí a necessidade, por exemplo, de trazer alguns dos aspectos essenciais da obra de Vigotski e seus colaboradores para que se possa entender/ descrever como essa criança vai construindo o seu conhecimento e se constituindo enquanto ser humano cognoscente.

A escolha pelos estudos numa perspectiva histórico-cultural, dialogando principalmente com Vigotski (1991, 1996, 1997, 2001 e 2007) e seus interlocutores, se deu essencialmente porque este teórico construiu as bases de sua teoria com sujeitos muito próximos daqueles com os quais lidamos cotidianamente no contexto sócio-educacional brasileiro, como destaca Góes (2002).

Além disso, Vigotski considerava que todos os seres humanos, independente de características físicas, mentais, sensoriais, sociais, são seres históricos e culturais, isto é, para Vigotski,

[...] os processos humanos têm gênese nas relaçôes sociais e devem ser compreendidos em seu caráter histórico-cultural. O homem significa o mundo e a si próprio náo de forma direta, mas por meio da experiência social. Sua compreensão da realidade e seus modos de agir são mediados pelo outro, por signos e instrumentos, isto é, são constituídos pela mediação social-semiótica. Assim, a formação do funcionamento subjetivo envolve a internalização (reconstrução, conversão) das experiências vividas no plano intersubjetivo. (GÓES, 2002, p. 99).

Nesse sentido, ao se tratar do contexto inclusivo de um bebê com síndrome de Down e seus processos de aprendizagem e desenvolvimento a fala de Góes, a partir do pensamento de Vigotski, conduz ao entendimento de que o bebê, independente de uma peculiaridade cromossômica, é um sujeito cognoscente, que faz parte de uma 
macrossociedade histórica e cultural e que, ao mesmo tempo em que se apropria das características dessa sociedade, deixa sua marca como sujeito também histórico, social e cultural, pois,

A criança é desde sempre um ser social, sendo que sua singularizaçáo como pessoa ocorre juntamente com sua aprendizagem como membro da cultura, ou seja, o desenvolvimento implica o enraizamento na cultura e a individuação. (GÓES, 2002, p. 99).

Ao considerar a criança como sujeito que aprende e se desenvolve nas relaçóes que estabelece na cultura e com os outros sujeitos que estấo ao seu redor, salienta-se que a criança com deficiência intelectual causada pela síndrome de Down, por exemplo, como ser humano genérico, apresenta como todos os outros sujeitos condiçóes de vida distintas, entretanto, marcadas por funçôes psicológicas que a diferenciam dos outros sujeitos. Nesse contexto, pode-se ressaltar que esta criança aprende e se desenvolve na medida em que desenvolve suas funçóes psicológicas superiores - percepção, linguagem, vontade, emoção, memória, pensamento, imaginação, dentre outras.

A partir de tais constataçóes, Vigotski (2001) salientava o essencial e importante papel que a educação formal tinha, e ainda tem, para que o sujeito se aproprie e desenvolva tais funçôes.

Assim, entende-se que no processo de experienciação da educação formal, quando esta é planejada de modo a possibilitar o acesso aos bens social e culturalmente desenvolvidos, a criança, independente de quaisquer particularidades pode aprender e se desenvolver.

Nesse ínterim, pensar no processo de aprendizagem e desenvolvimento que culmina com a inclusão do bebê com síndrome de Down na educação infantil é pensar, a partir dos pressupostos vigotskianos, que a marca desse processo se dá na e pela linguagem, perpassada pelas relaçóes intersubjetivas que envolvem tanto crianças-crianças quanto adulto-criança, já que como destaca Pino (2005), é por meio desse processo de trocas interpessoais que nos tornamos seres humanos, para além de vinculações biológicas, mas seres humanos sociais.

Desse modo, o processo inclusivo, nessa perspectiva teórica, deve levar em consideração que o modo como a escola se organiza, o modo como as relaçóes interpessoais se estabelecem, o modo como a aprendizagem é concebida, além do modo como a criança é concebida em sua singularidade, são quesitos importantíssimos de serem observados, já que, "o déficit orgânico não pode ser ignorado, mas é a vida social que abre possibilidades ilimitadas de desenvolvimento cultural”. (GÓES, 2002, p. 100).

\section{Considerações metodológicas do estudo desenvolvido}

$\mathrm{O}$ estudo que deu origem a este artigo foi desenvolvido a partir da natureza qualitativa, assumindo o panorama do estudo de caso com enfoque descritivo numa perspectiva histórico-cultural, pois de acordo com Michel (2009, p. 53), "é uma técnica utilizada em pesquisas de campo com o objetivo de compreender o sujeito 
da pesquisa em seus próprios termos, ou seja, no seu próprio contexto". Exige estudo aprofundado a fim de se reunir o maior número de informações sobre o tema de interesse, consequentemente, possibilita um maior aprofundamento, acompanhamento e aprendizado sobre o sujeito pesquisado, tornando assim, uma pesquisa mais rica em informaçóes, detalhes, dentre outros aspectos.

A opção pelo estudo de caso com ênfase na descrição se deu, portanto, pelo fato de que o sujeito investigado é um caso isolado e também pelo fato de que os dados que foram produzidos, possivelmente, são múltiplos (palavras, silêncios, olhares, sons, expressões, objetos, movimentos, imagens, dentre outros), logo o propósito desta pesquisa não foi levantar um único dado e, sim, compreender e descrever como o processo de inclusão desse sujeito acontece, a partir do envolvimento com o contexto in loco.

Para obter dados suficientes ao desenvolvimento e alcance dos objetivos, este estudo utilizou os seguintes procedimentos para produção de dados: observação participante do cotidiano escolar com registro em diário de campo; entrevista semiestruturada e/ou conversas informais com os sujeitos da pesquisa; fotografias e filmagens.

O estudo foi desenvolvido em um Centro de Educação Infantil federal denominado de CEI Criarte. A escolha por desenvolver o estudo numa escola federal de educação infantil se deu pelos seguintes aspectos: a) não foram encontrados estudos que tivessem como foco analítico bebês com síndrome de Down em processo de inclusão em tais espaços; b) pelo fato de que o estado do Espírito Santo possui somente um centro de educação infantil pertencente à rede federal de educaçáo; c) por ter em seu quadro discente um bebê com síndrome de Down matriculado; d) por se constituir num campo/temática inéditos de pesquisa; e) pela disponibilidade e interesse da família.

Foram sujeitos dessa pesquisa, de modo direto, ou seja, onde o contato não se deu somente por meio de entrevistas, mas a partir das observaçóes participantes, conversas informais, fotografias e filmagens: a) o bebê com síndrome de Down em processo de inclusáo; b) as professoras regente dos Grupos 1 e 2 em que o bebê esteve matriculado; c) a diretora do CEI - Criarte; d) mãe do bebê.

\section{bebê com síndrome de Down na educação infantil}

A partir do estudo desenvolvido destacamos que quando se fala em aprendizagem e desenvolvimento numa perspectiva sócio-histórica nos remetemos ao fato de que para Vigotski (1996, p. 31), “[...] os primeiros pontos de apoio que encontra a criança para sua futura criação é o que vê e o que ouve, acumulando materiais dos quais logo usará”. Além disso, salientamos que para esse autor o processo de aprendizagem, quando bem organizado, leva ao desenvolvimento, suscitando uma série de combinaçóes que produzem as chamadas zonas de desenvolvimento proximais.

Nesse contexto, a partir do momento em que a criança com ou sem deficiência entra em contato de maneira sistemática com o mundo social, histórico e cultural que a cerca, com os outros seres humanos, com as ferramentas criadas, passa, pela via 
da mediação, a se apropriar das características tipicamente humanas e a se desenvolver também sistematicamente, pois, como alerta Vigotski (2001, p. 484),

[...] o indício substancial da aprendizagem é de que ela cria uma zona de desenvolvimento imediato, ou seja, suscita para a vida na criança, desperta e aciona uma série de processos interiores de desenvolvimento. Atualmente esses processos são possíveis para a criança só no campo das inter-relaçóes com os que a rodeiam e da colaboraçáo com os colegas, mas, ao prolongar o processo interior de desenvolvimento, elas se tornam patrimônio interior da própria criança. [...] a aprendizagem não é desenvolvimento, mas, corretamente organizada, conduz o desenvolvimento mental da criança, suscita para a vida uma série de processos que, fora da aprendizagem se tornariam inteiramente inviáveis.

Nesse movimento apresentado, o professor e a escola assumem uma característica de extrema importância para garantir o êxito do processo de ensino e aprendizagem, pois, "Ao organizar o meio e a vida da criança nesse meio, o pedagogo interfere ativamente nos processos de desenvolvimento dos interesses infantis e age sobre eles da mesma forma que influencia todo o comportamento das crianças". (VIGOTSKI, 2001, p. 163)

No Centro de Educação Infantil que serviu de base para nosso estudo percebemos que os profissionais têm trabalhado no sentido de possibilitar a organização do ambiente escolar para que o bebê com síndrome de Down, bem como as crianças de modo geral que habitam tal espaço, se apropriem das ferramentas tipicamente humanas e possam transformar suas funçôes psicológicas inferiores em superiores, ou seja, se humanizar, aprender, desenvolver.

A partir dos dados produzidos destacamos que o bebê com síndrome de Down está em processo ininterrupto, dialético e profundo de aprendizado e desenvolvimento, na medida em que tem se apropriado das características tipicamente humanas pelo contato com o outro e com o conhecimento sistematicamente organizado.

No que tange à presença do bebê com síndrome de Down na educação infantil pode-se salientar que essa presença é de extrema importância para a humanização do ser humano, uma vez que o ser humano se torna humano na medida em que se apropria das características tipicamente humanas no contato direto com os outros seres de sua espécie, ou seja, através dos outros constituímo-nos ininterruptamente.

De acordo Pino (2005) e Martins (2009), o bebê com ou sem deficiência é um sujeito que se desenvolve a passos largos a partir do momento em que é inserido e interage como ser produtor de história e cultura. Isto é,

[...] a relação da criança com a realidade circundante é social desde o principio. Deste ponto de vista podemos definir o bebê como um ser maximamente social. Toda relaçáo da criança com o mundo exterior, inclusive a mais simples, é a relaçáo refretada por meio da relaçáo com outra pessoa. A vida do bebê está organizada de tal modo que em todas as relaçóes se faz presente de maneira visível ou invisível outra pessoa. [...]. Todo trabalho com bebê deve levar 
em conta este fato e ampliar as possibilidades de apresentação da realidade externa enriquecendo seu estado de vigília. (MARTINS, 2009, p. 101-102).

Levando em consideração o que Martins (2009) destaca sobre o trabalho com bebês na educação infantil, pode-se enfatizar que a educação infantil precisa ser um lugar onde o ser humano de pouca idade entre em contato com um leque rico de experiências sociais, culturais, intelectuais, físicas, motoras, psicológicas, dentre outras que possibilitem essa inserção irrestrita no mundo, pois "Desde as primeiras semanas de vida do ser humano manifesta-se a lei geral do desenvolvimento psíquico: as açóes externas vividas socialmente vão sendo interiorizadas pelo sujeito e vão se tornando ações internas". (MELLO, 2006, p. 197)

A partir das falas das professoras e das observaçóes realizadas percebemos que a questão da família, por exemplo, é algo bem presente no CEI Criarte, pois tudo que é realizado para benefício da criança, para melhorar seu processo de aprendizagem e desenvolvimento, é passado para os pais, ou em reunióes formais, ou em conversas informais.

Nesse contexto analítico, quando questionados sobre o entendimento acerca da educação infantil, os entrevistados assim se posicionaram:

É um processo de vida superinteressante de ensino e aprendizagem. Temos que ter bem claro que não é um ambiente somente para cuidar (PROFESSORA ROSA).

Educação infantil é um direito da criança. Agora com essa ampliação para os 4 anos, acho que isso favorece os novos debates, o novo olhar para a educação infantil, deixar de ser aquela coisa assistencialista, que a educaçáo infantil seja um local onde as crianças possam experimentar as brincadeiras, possam interagir com o outro, ter os momentos do coletivo, mas que ela possa também expressar sua individualidade dentro desse coletivo. Educaçáo infantil para mim é isso! (PROFESSORA MARGARIDA).

Essas falas nos revelam que as professoras entrevistadas têm uma ideia de educação infantil que assume o caráter de primeira etapa da educação básica não como preparatória para o ensino fundamental, mas como uma etapa educacional onde o sujeito criança, independente de quaisquer características, é visto como sujeito e foco da ação, logo há um planejamento a ser executado, uma sistematização de práticas e ações, um projeto a ser implementado.

No que se refere à inclusão escolar do bebê com síndrome de Down na educação infantil, percebe-se que esse ainda é um processo muito novo, entretanto, vale salientar que a legislação brasileira (BRASIL, 1996; 2008; 2014) estabelece que a inclusão escolar dos sujeitos público-alvo da educação especial, e nesse grupo incluídos os que apresentam síndrome de Down, deve ocorrer desde a educação infantil.

Sendo a educação infantil primeira etapa da educação básica e a educação especial uma modalidade educacional que perpassa todos os níveis, etapas e modalidades da educaçáo brasileira desde a mais tenra idade, percebe-se que o processo de inclusão escolar não pode ficar à margem daquilo que reza a legislação. Ou seja, 
A educação inclusiva supóe que o objetivo da inclusão educacional seja eliminar a exclusão social, que é consequência de atitudes e respostas à diversidade de raça, classe social, etnia, religiáo, gênero e habilidade. [...]. A inclusão começa a partir da crença de que a educação é um direito humano básico e o fundamento para uma sociedade mais justa. (AINSCOW, 2009, p. 11-12).

Quando questionados sobre suas concepçóes acerca da inclusão escolar de Lucas no CEI Criarte, as entrevistadas revelam uma visão meio contraditória acerca da educação especial numa perspectiva da educação inclusiva. As entrevistadas parecem ao mesmo tempo conhecer e desconhecer os fundamentos, as nuances, as perspectivas relacionadas a pessoas com deficiência e no caso, sujeitos com síndrome de Down, bebês. Ambas fazem um trabalho que consideramos inclusivo, porém parece não terem consciência desse fato.

Em relação à educação inclusiva, esse termo precisa se voltar para a escola como uma discussão maior, até mesmo de que está na linha da educação inclusiva discutindo isso e trazer para as escolas professores conceitos novos sobre a educação inclusiva. Eu percebo as diferenças de Lucas e as limitaçóes dele. O que a gente pode fazer diante dessas limitaçóes dele e como as outras crianças têm, mas eu também tenho meus limites teóricos, metodológicos. A gente precisa de ajuda até conceitual para entender um pouco melhor sobre essa educação. (PROFESSORA ROSA).

A Educação inclusiva creio que é um olhar diferenciado na nossa prática, aquele aluno que está ali, um olhar atento, a escuta mais atenta. Não só o aluno estar naquele local, mas para além de estar naquele local, o que eu tenho dado de oportunidade para o meu aluno? Como tenho ouvido? Como tenho olhado para esse aluno? Ele chega feliz? Sai feliz da Escola? Gosta de estar na escola? Se identifica com os coleguinhas? Os coleguinhas o aceitam naquela brincadeira? Está ali perto dele aceitando brincar com ele, brincando junto, eu acho que quando a gente fala de educação inclusiva é essa questão do olhar, da prática que nós vamos fazer com essa criança, sobre as demais que estão ali, é isso! (PROFESSORA MARGARIDA).

A perspectiva da educação inclusiva é pensar na escola numa outra lógica que reconheça a diferença e que essa diferença seja mola propulsora de novas açôes que façam com que esses sujeitos participem de modo global e irrestrito do cotidiano escolar e isso era exatamente o que ocorria cotidianamente.

Observamos que Lucas participava do cotidiano escolar como sujeito ativo, criativo, produtor de história e cultura, como bem salienta Vigotski. Lucas era potencializado constantemente a ler gravuras, a ouvir e representar músicas e histórias infantis, a fazer os passeios culturais organizados pela escola, a interagir com os demais colegas nos espaços internos e externos do ambiente escolar.

Portanto, nesse contexto, pensar uma escola inclusiva e a inclusão de bebês com deficiência pressupóe-se que se reconheça e se valorize a diversidade como um processo favorecedor de aprendizagens significativas, ou seja, "A ênfase deve recair 
sobre a identificação de suas possibilidades, culminando com a construção de alternativas para garantir condiçóes favoráveis à sua autonomia escolar e social, enfim, para que se tornem cidadãos de iguais direitos". (PRIETO, 2006, p. 40)

A nosso ver, as ações desenvolvidas com foco na inclusão escolar de Lucas encontram eco na fala da família, quando sua mãe salienta que:

Eu penso assim, um pouco da experiência que a gente tem com
o Lucas, seria um entendimento próximo a esse que temos, que
é onde você, a criança entra numa instituiçáo, onde ela é aten-
dida como o público em geral, não em tratamento que seja para
todos, mas tem atendida todas as suas necessidades especiais, se
pensa nos casos individuais a escola hoje ela tem uma variedade
de pessoas advindas de família e com necessidades táo diversas que
isso é muito difícil. Então, penso na inclusão uma escola que tem
muitos alunos, entáo, inclusáo é o que a gente vê um pouco aqui
na Criarte (LAURA - MÃE DO LUCAS).

Essa fala demonstra que a educação inclusiva, quando bem conduzida pode ser uma via de reconhecimento do outro como sujeito sócio-histórico-cultural, como ser humano genérico que, independente de características físicas, sensoriais ou intelectuais, é capaz de se transformar e transformar o ambiente a partir do momento em que é visto como mais um sujeito que compóe a coletividade.

Em relação às práticas pedagógicas cotidianas com bebês na educação infantil com ou sem deficiência, temos percebido nos estudos realizados que a prática cotidiana potencializava o sujeito para que vencesse obstáculos diários, desde aspectos como a higiene pessoal até aspectos relacionados ao aprendizado de conteúdos curriculares próprios da educação infantil.

O precesso de observação participante desenvolvido na pesquisa deu-se pelo período de um anos, sento o segundo semestre de 2014, quando o bebê estava matriculado no Grupo 1; e no primeiro semestre de 2015, quando estava matriculado no Grupo 2. Assim, pode-se ter uma ideia bem ampla daquilo que era desenvolvido com o bebê e seu processo de desenvolvimento cognitivo, motor, linguístico, dentre outros aspectos.

Observamos momentos de brincadeira, garantindo a ampliação de experiências que possibilitem movimentação; expressão artística e física; imersão em diferentes linguagens, como a histórica, geográfica, matemática, dentre outras; convívio com diferentes ambientes culturais, como museus, galerias de arte; estímulo à autonomia, por meio do incentivo ao cuidado pessoal, à independência na alimentaçáo; experiências éticas e estéticas, dentre uma série de aspectos vivenciados pelo bebê que contribuíram para que passasse a fazer uso da linguagem oral e gestual para indicar suas necessidades, gostos, memória, interesses e desejos.

No CEI Criarte, lócus desse estudo, percebemos que as práticas pedagógicas desenvolvidas tanto no Grupo 1 quanto no Grupo 2 com Lucas e as demais crianças, de acordo o que se é esperado para a educação infantil, seguem aquilo que é explicitado pelos documentos norteadores para a educação infantil, além de mostrarem um 
entendimento teórico e metodológico alicerçado em bases sustentadas na teoria, ou seja, não é um fazer qualquer, mas um fazer que segue uma linha de raciocínio, onde a criança ocupa o papel de protagonista das açóes.

\section{Considerações finais}

No que se refere ao primeiro objetivo elencado para esse estudo, percebemos que o sujeito com síndrome de Down apresenta características, peculiaridades e particularidades que são próprias do acidente cromossômico que causa (ainda sem conclusão médica) a síndrome de Down. Tais características estấo descritas nesse texto seguindo uma via biológica. Entretanto, ao adentrar o cotidiano do CEI Criarte, percebemos que as características náo eram impeditivo para seu exercício como sujeito cognoscente. Pelo contrário, suas características eram percebidas como mais uma das múltiplas que todo ser humano possui.

Lucas era visto e percebido como sujeito que aprende, se desenvolve, interage, produz conhecimento, cultura, história, como qualquer ser humano. Além disso, pôde-se perceber que ele era desafiado o tempo todo a superar seus limites.

Em relação ao segundo objetivo percebemos que as práticas pedagógicas realizadas no CEI Criarte estão muito próximas àquilo que os estudos com foco na inclusão escolar de crianças público-alvo da educação especial têm dito (MANTOAN, 2007; DRAGO, 2011).

Salientamos que em momento algum percebemos práticas que inviabilizassem a participação plena de Lucas, ao contrário, como dito anteriormente ele era instigado a participar de todos os momentos das atividades, porém sendo respeitado como criança que tem limitaçóes próprias de sua idade, mesmo salientando que não houve adaptaçấo alguma dos espaços escolares. Ao contrário, Lucas era instigado a vencer seus limites, a andar, correr, vasculhar, buscar.

Mesmo não sendo identificado o atendimento educacional especializado no contraturno para o trabalho com Lucas, percebemos que as práticas pedagógicas desenvolvidas cotidianamente davam conta de conduzi-lo ao desenvolvimento de suas funçōes psicológicas superiores, na medida em que participava ativamente de tudo aquilo que era proposto. Além disso, destacamos que as práticas pedagógicas desenvolvidas com Lucas encontram eco na perspectiva vigotskiana, pois a mediação do adulto era uma constante e, esse processo conduz ao desenvolvimento das formas superiores de comportamento, já que "A formação das funçóes psicológicas superiores é decorrente do caráter mediatizado da atividade humana” (FACCI, 2006, p. 126).

Em que pese ao terceiro objetivo proposto nesse estudo, evidenciamos que o CEI Criarte tem uma organizaçáo didático-pedagógica que tem atendido aos pressupostos legais (BRASIL, 1998, 2009, 2010) no que tange à educação infantil como primeira etapa da educação básica, bem como no que se refere à educação especial na perspectiva da educação inclusiva (BRASIL, 2008).

Nesse sentido, percebe-se que sendo uma escola de educação infantil federal, esta náo tem se diferenciado das demais escolas que atendem tanto aos alunos públi- 
co-alvo da educação especial quanto os da educação infantil, no sentido de garantir o acesso aos conhecimentos historicamente acumulados pela humanidade aos seus sujeitos, bem como garantindo que a criança seja vista como sujeito de direitos, cidadá, com voz e vez no processo educativo.

\section{Referências}

AINSCOW, M. Tornar a educaçáo inclusiva: como esta tarefa deve ser conceituada? In: FÁVERO, O. et al. Tornar a educaçáo inclusiva. Brasília: Unesco, 2009. P. 11-23.

ARIÉS, P. História social da criança e da família. 2.ed. Rio de Janeiro: Guanabara, 1981.

BOGDAN, R.; BIKLEN, S. Investigaçáo qualitativa em educaçáo. Portugal: Porto Editora, 1994.

BRASIL. Lei de Diretrizes e Bases da Educaçáo Nacional 9394. Brasília, 1996.

BRASIL. Referencial Curricular Nacional para a Educaçáo Infantil. Brasília: MEC, 1998.

BRASIL. Política Nacional de Educação Especial na Perspectiva da Educaçáo Inclusiva. Brasília: MEC, 2008.

BRASIL, Indicadores da Qualidade na Educaçáo Infantil. Brasília: MEC, 2009.

BRASIL. Diretrizes Curriculares Nacionais para a Educaçáo Infantil. Brasília: MEC, 2010.

BRASIL. Plano Nacional de Educaçáo. Brasília, 2014.

DRAGO, R. Inclusão na educaçáo infantil. Rio de Janeiro: WAK, 2011.

FACCI, M. G. D. Vigotski e o processo ensino-aprendizagem: a formação de conceitos. In: MENDONÇA, S. G. L. MILLER, S. (Orgs.). Vigotski e a escola atual: fundamentos teóricos e implicaçôes pedagógicas. Araraquara: Junqueira \& Marin, 2006. P. 123-148.

GÓES, M. C. R. de. Relaçôes entre desenvolvimento humano, deficiência e educação: contribuiçôes da abordagem histórico-cultural. In: OLIVEIRA, M. K. et al. Psicologia, educaçáo e as temáticas da vida contemporânea. São Paulo: Moderna, 2002. P. 95-114.

GÓES, M. C. R. de.. As relaçôes intersubjetivas na construção de conhecimentos. In: GÓES, M. C. R. de.; SMOLKA, A. L. B. (Org.). A significação nos espaços educacionais: interação e subjetivação. São Paulo: Papirus, 1997. P. 11-28.

KRAMER, S.. Infância, cultura contemporânea e educação contra a barbárie. In: BAZÍLIO, L. C.; KRAMER, S. Infância, educação e direitos humanos. São Paulo: Cortez, 2003. P. 83-106.

MANTOAN, M. T. E. Educação inclusiva: orientaçôes pedagógicas. In: FÁVERO, E. A.; PANTOJA, L. de M. P.; MANTOAN, M. T. E. (ORG.) Atendimento educacional especializado: aspectos legais e orientaçóes pedagógicas. Brasília: SEESP/SEED/MEC, 2007. p. 45-56.

MARTINS, L. M. O ensino e o desenvolvimento da criança de zero a três anos. In: ARCE, A.; MARTINS, L. M. (Org.). Ensinando aos pequenos de zero a três anos. Campinas: Alínea, 2009. P. 93-120.

MELLO, S. A. Contribuições de Vigotski para a educação infantil. In: MENDONÇA, S. G. de L.; MILLER, S. (Org.). Vigotski e a escola atual: fundamentos teóricos e implicaçóes pedagógicas. Araraquara: Junqueira \& Marin, 2006. P. 193-202.

MENDES, E. G. Perspectivas para a construção da escola inclusiva no Brasil. In: PALHARES, M. S.; MARINS, S. (Org.). Escola inclusiva. São Paulo: EDUFSCAR, 2002. P. 61-85.

MICHEL, M. H. Metodologia e Pesquisa Científica em Ciências Sociais. 2. Ed. São Paulo, Atlas, 2009.

PINO, A. As marcas do humano: as origens da constituiçáo cultural da criança na perspectiva de Lev S. Vigotski. São Paulo: Cortez, 2005.

PRIETO, R. G. Atendimento Escolar de Alunos com Necessidades Educativas Especiais: um olhar sobre as políticas públicas de educação no Brasil. In: ARANTES, V. A. (Org.). Inclusão escolar. São Paulo: Summus, 2006. P. 31-103.

PUESCHEL, S. (Org.). Síndrome de Down: guia para pais e educadores. 7.ed. São Paulo: Papirus, 1993.

VIGOTSKI, L. S. A formaçáo social da mente. São Paulo: Martins Fontes, 2007. 
Rogério Drago - Israel Rocha Dias

VIGOTSKI, L. S. Obras escogidas. Fundamentos da defectologia. Tomo V. Madri: Visor, 1997.

VIGOTSKI, L. S. A formaçáo social da mente. São Paulo: Martins Fontes, 1991.

VIGOTSKI, L. S. La imaginación y el arte em la infância. Madri: Akal, 1996.

VIGOTSKI, L. S. Psicologia pedagógica. São Paulo: Martins Fontes, 2001.

VOIVODIC, M. A. Inclusáo escolar de criança com Síndrome de Down. Petrópolis: Vozes, 2007.

\section{Correspondência}

Rogério Drago - Universidade Federal do Espirito Santo, Departamento de Teorias do Ensino e Práticas Educacionais. Av. Fernando Ferrari, 514, Centro de Educação, sala 69, Goiabeiras. CEP: 29075-510. Vitoria, Epírito Santo, Brasil.

E-mail: rogerio.drago@gmail.com - isrocha30@gmail.com

Recebido em 03 de outubro de 2016

Aprovado em 14 de junho de 2017 